\title{
Is there a relationship between the detection of human herpesvirus 8 and Epstein-Barr virus in Waldeyer's ring tissues?
}

\author{
Cristiano Aparecido Chagas ${ }^{a}$, Luiza Hayashi Endo ${ }^{b}$, \\ Washington Luís Conrado dos-Santos ${ }^{c}$, Glauce Aparecida Pinto ${ }^{a}$, \\ Eulália Sakano $^{\mathrm{b}}$, Pierre Brousset ${ }^{\mathrm{d}}$, José Vassallo ${ }^{\mathrm{e}, *}$
}

\author{
a Laboratory of Experimental Pathology, Centro de Assistência Integral à Saúde da Mulher, \\ State University of Campinas (UNICAMP), São Paulo, Brazil \\ ${ }^{\mathrm{b}}$ Department of Otorhinolaryngology, Faculty of Medical Sciences, UNICAMP, SP, Brazil \\ ' Centro de Pesquisas Gonçalo Muniz, FIOCRUZ, Salvador, Bahia, Brazil \\ ${ }^{\mathrm{d}}$ Laboratory of Pathology, University of Toulouse, Toulouse, France \\ e Department of Anatomical Pathology, Faculty of Medical Sciences, UNICAMP, P.O. Box 6111, \\ CEP 13083-970, Campinas, SP, Brazil
}

Received 3 May 2006; received in revised form 28 June 2006; accepted 28 June 2006

\author{
KEYWORDS \\ Human herpesvirus 8; \\ Epstein-Barr virus; \\ Tonsils; \\ Adenoids; \\ In situ hybridization
}

\begin{abstract}
Summary
Objective: Human herpesvirus 8 (HHV-8) and Epstein-Barr virus (EBV) are human pathogens associated to a number of neoplasms, including tumors of the Waldeyer's ring. Both viruses have been previously detected by in situ methods in tonsils and adenoids from children. HHV-8 was found in $6.8 \%$ of the cases and EBV in about one third of the cases. As they belong to the same $\gamma$-herpesvirus subfamily and share some biological characteristics, it is of medical interest to further explore their possible relationship in the Waldeyer's ring, an issue not yet addressed in the specialized literature. The purpose of the present study is to compare the presence of EBV by in situ hybridization (ISH) in tonsils and adenoids from children up to 14 years of age in cases previously shown to be positive and negative for HHV-8.

Methods: Paraffin wax-embedded sections consisting of 38 tonsils and two adenoids from 40 patients were analyzed. HHV- 8 was detected by ISH, using the T1-1 probe for the viral mRNA. EBV was also detected by ISH, using the EBER probe. Both probes and the detection systems were provided by Novocastra.

Results: HHV-8 was detected in 19 tonsils and one adenoid. The other 19 tonsils and one adenoid taken from the HHV-8-negative group were selected by pairing age and
\end{abstract}

\footnotetext{
* Corresponding author. Tel.: +55 193289 3897; fax: +55 1932893897.

E-mail address: glaujv@fcm.unicamp.br (J. Vassallo).
} 
gender of patients with the HHV-8-positive group. In both groups EBV was detected in 13 cases and was negative in other 7 .

Conclusion: Although both viruses are related in many aspects, some biological and epidemiological features differ. This is reflected in the present results, as EBV is similarly detected in the groups negative and positive for HHV-8, favoring different mechanisms of spread.

(C) 2006 Elsevier Ireland Ltd. All rights reserved.

\section{Introduction}

Human herpesvirus 4, best known as Epstein-Barr virus (EBV) and the human herpesvirus type 8 (HHV-8, also known as Kaposi sarcoma herpesvirus, $\mathrm{KSHV}$ ) belong to the $\gamma$-herpesviridae subfamily $[7,8,12,13]$. Both are clinically relevant, as they represent pathogens associated with human nonneoplastic and neoplastic diseases. Medical importance of these viruses is reflected by the ever-growing list of studies available. EBV is associated with Hodgkin's disease in half of the cases (even more frequently in children), with polyclonal lymphoproliferations and with malignant non-Hodgkin's lymphomas, especially in patients infected by the human immunodeficiency virus (HIV). In the Waldeyer's ring, EBV is found in all cases of undifferentiated nasopharyngeal carcinomas and T/NK lymphomas. HHV8 has been associated with Castleman's disease and neoplasms, such as Kaposi's sarcoma (KS), and pleural effusion lymphoma. KS is described to occur in African infants, even prior to the HIV epidemic, and which now represents one of the leading cancers in HIV+ children $[6,15]$. Research on viruses that have oncogenic potential, especially in children, are important both to alert physicians to the possibility that such lesions may appear in other regions of the world, especially if a supervening immune suppression takes place, and for the development of prophylactic or therapeutic measures.

In previous studies addressing the detection of members of the Herpesviridae family in tonsils and adenoids using in situ histomolecular techniques, it was demonstrated that the Epstein-Barr virus (EBV) was present in about $30 \%$ of the tonsils and adenoids [9-11]. In contrast, in none of the 36 cases studied by us could herpesviruses 1 and 2 (HSV-1/2) be found [18].

More recently, we investigated tonsils and adenoids from 293 patients for the presence of human herpesvirus 8 (HHV-8) and found that $6.8 \%$ were positive [5]. Virus was mainly found in lymphoid cells, and more rarely in epithelial cells, as it was also observed for EBV [9-11]. In that study, we were able to support the evidence of an oral route of contamination by HHV-8, as it is the case for EBV and HSV-1/2 [5,6,15].
Thus, EBV and HHV-8, but not HSV-1/2, seem to share the organs of the Waldeyer's ring as a site of prolonged residency, according to these findings. However, two differences are noticeable: first, EBV is more frequently found in adenoids and tonsils, perhaps reflecting the more widespread distribution of this virus in the general population. In addition, EBV was detected in $29.4 \%$ of tonsils from children aged $2-14$ years and in $33 \%$ of adenoids from children aged $1-2$ years, whereas HHV- 8 was detected in 19/ $181(10.4 \%)$ tonsils and in just one out of 162 adenoids $(0.06 \%)[5,9,10]$. Then, a clear difference in the preference of both lymphoid organs seems to exist. On the other hand, in both cases, younger children present more frequently EBV and HHV-8 positive cells in comparison with older ones [5,9]. A selected list of similarities and differences between EBV and HHV-8 are summarized in Table 1.

Table 1 Summary of similarities and differences between EBV and HHV-8

Similarities

Both belong to the $\gamma$-herpesviridae subfamily and share close similarities in their genomes

Latent infection of lymphoid and epithelial cells of the Waldeyer's ring

Implication in the pathogenesis of lymphoproliferative disorders

Increasing evidence of similar transmission by saliva and, in some extent, also by genital secretions

Detection of infected cells by in situ hybridization in the Waldeyer's ring tend to decrease with age

Differences

Viral and cell receptors interactions responsible for internalization of the viruses differ

HHV-8 does not immortalize lymphoid B-cells in vitro, as does EBV

HHV-8 seems to have a net predilection for the tonsils and not for adenoids; EBV does not show this preference

EBV is ubiquitous, infecting more than $90 \%$ of the population worldwide; HHV-8 infects predominantly populations of poorer regions of the planet

Environmental and constitutional factors probably differ, as detection of infected cells by in situ hybridization in the Waldeyer's ring are unrelated (present study) 
The medical importance of both herpeviruses and the correlations between EBV and HHV-8 extracted from our previous data, allied to the lack of studies concerning the possible relationship (environmental or constitutional factors) of each other related to their detection in the Waldeyer's ring, impelled us to compare the frequency of positivity for both viruses. EBV was detected in tonsils and adenoids among known HHV-8-positive and negative children, as determined in our previous study [5]. For their detection the in situ hybridization (ISH) technique was used on paraffin embedded tonsils and adenoids sections. It was our purpose to verify if there is a relationship between the two infections in the tonsils.

\section{Materials and methods}

Thirty-eight tonsils and two adenoids from 40 patients were analyzed. Paraffin wax-embedded tissue was obtained from the files of the Department of Anatomical Pathology. Indications for the resection of tonsils and adenoids were airway obstruction by hypertrophy and recurrent tonsillitis. In every case, a florid lymphoid follicular hyperplasia was observed at histology. Age ranged from 1 to 14 years, median 3.5 years. Twenty-six were male and 14 female. HHV-8 had been previously detected by $\mathrm{ISH}$ in all patients, 38 in the tonsils and 2 in the adenoids. EBV was then detected by ISH. In order to evaluate the relationship between the detection of both viruses two groups were compared: (1) a group of 20 patients which had already been shown positive for HHV-8 [5] and (2) a group consisting of HHV-8 negative cases, paired by age and gender with the first group (Table 2).

For the ISH technique, tissue sections were dewaxed, hydrated and treated with proteolytic enzyme (proteinase $\mathrm{K}, 15 \mathrm{~min}$ at $37^{\circ} \mathrm{C}$ ). Sections were incubated over night $(16-20 \mathrm{~h})$ at $37^{\circ} \mathrm{C}$ with a probe complementary to the mRNA of HHV-8 (T1-1, code NCL-HHV-8, Novocastra Laboratories, Newcastle, UK) or with a probe to the early RNAs of EBV (EBER 1 and 2, Novocastra). The revelation of the reaction was performed by using the detection kit, according to the manufacturer's instructions (code $\mathrm{NCL}-\mathrm{ISH}-\mathrm{D}$, Novocastra). Labelling consisted of a nuclear blue-black dark staining.

The positive controls consisted of a sample of Kaposi's sarcoma for HHV- 8 and a nasopharingeal undifferentiated carcinoma for EBV, which had been previously tested and showed positive staining. In negative controls the specific probes were replaced by bovine serum albumin (BSA $1 \%$ in phosphatebuffered saline, $\mathrm{pH} \mathrm{7.6)}$. The presence of reactivity
Table 2 Expression of EBV in cases positive and negative for HHV-8

\begin{tabular}{rrlll}
\hline Case & Age & Sex & $\begin{array}{l}\text { EBV IN } \\
\text { HHV-8+ }\end{array}$ & $\begin{array}{l}\text { EBV IN } \\
\text { HHV-8- }\end{array}$ \\
\hline $1^{*}$ & 1 & $\mathrm{M}$ & 0 & 1 \\
2 & 9 & $\mathrm{M}$ & 0 & 0 \\
3 & 4 & $\mathrm{M}$ & 2 & 2 \\
4 & 2 & $\mathrm{~F}$ & 0 & 0 \\
5 & 5 & $\mathrm{~F}$ & 1 & 1 \\
6 & 3 & $\mathrm{M}$ & 1 & 3 \\
7 & 4 & $\mathrm{M}$ & 0 & 0 \\
8 & 6 & $\mathrm{M}$ & 0 & 0 \\
9 & 6 & $\mathrm{~F}$ & 1 & 1 \\
10 & 3 & $\mathrm{M}$ & 2 & 1 \\
11 & 6 & $\mathrm{~F}$ & 0 & 1 \\
12 & 1 & $\mathrm{~F}$ & 3 & 0 \\
13 & 5 & $\mathrm{~F}$ & 0 & 1 \\
14 & 2 & $\mathrm{M}$ & 2 & 2 \\
15 & 2 & $\mathrm{M}$ & 2 & 1 \\
16 & 3 & $\mathrm{~F}$ & 3 & 2 \\
17 & 3 & $\mathrm{M}$ & 1 & 0 \\
18 & 2 & $\mathrm{M}$ & 2 & 3 \\
19 & 14 & $\mathrm{M}$ & 1 & 0 \\
20 & 4 & $\mathrm{M}$ & 2 & 1 \\
\hline
\end{tabular}

Case $1^{*}$ is the only case in which expression of HHV-8 occurred in adenoidal tissue. Differences were not statistically significant (non parametric Mann-Whitney test, $p=0.67$ ).

on sections was analyzed using an optic microscope and scored as follows:

$0=$ no staining;

$+=$ less than 5 positive cells in the section;

$++=6$ to 15 positive cells in the section;

$+++=$ more than 15 positive cells in the section.

To compare both groups, the non parametric Mann-Whitney test was used.

\section{Results}

In both groups EBV was detected in 13 cases and was negative in other 7 (Tables 2 and 3). In the group of cases positive for HHV-8, five patients were scored + , six ++ and two +++. In the group of cases negative for HHV-8, eight patients were scored +, three ++ and two +++. Fig. 1 illustrates one case with rare

Table 3 Total numbers of expression of EBV according to HHV-8 status

\begin{tabular}{llcl}
\hline & EBV + & EBV - & Total \\
\hline HHV-8+ & 13 & 7 & 20 \\
HHV-8- & 13 & 7 & 20 \\
Total & 26 & 14 & 40 \\
\hline
\end{tabular}




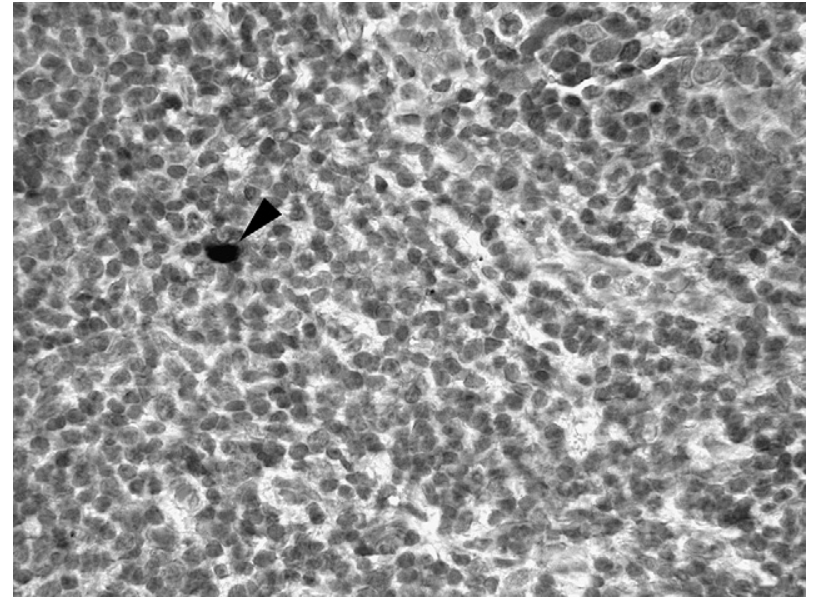

Fig. 1 Rare cells are positive for EBV (score +). Arrowhead points to a positive activated lymphoid nucleus, while all other lymphocytes are negative. (EBER $1 / 2$ probe, in situ hybridization, $\times 400$ ).

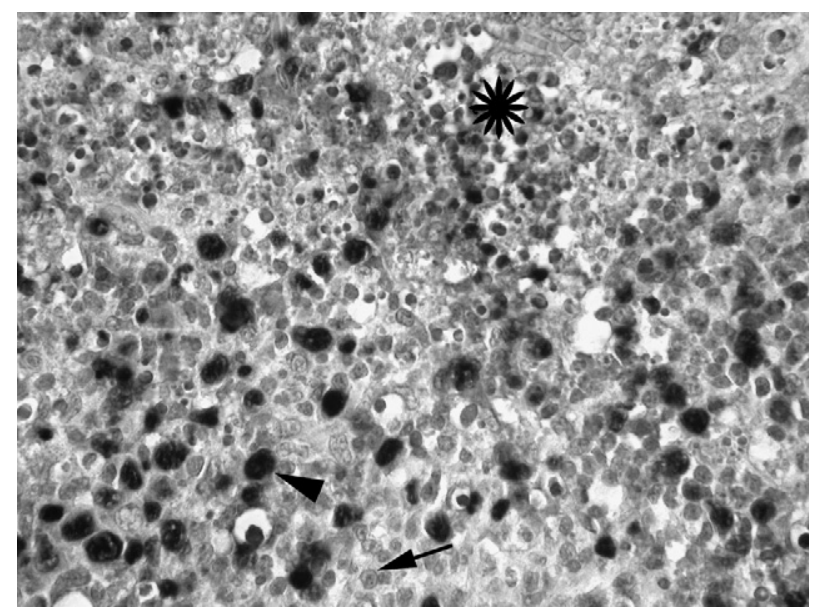

Fig. 2 In one case more than 15 nuclei were positive for EBV (score +++ ). Arrowhead points to one of the many positive activated lymphoid nuclei. Arrow points to one negative activated lymphoid cell. Asterisk indicates an area with many apoptotic cells (small cellular debris), probably due to massive viral infection. (EBER $1 / 2$ probe, in situ hybridization, $\times 500)$.

positive cells for EBV. Fig. 2 illustrates one case with more than 15 positive nuclei, with many apoptotic cells, probably due to massive viral infection.

\section{Discussion}

Our results show that, in spite of many similarities, detection of EBV and HHV-8 in the Waldeyer's ring is not correlated. EBV and HHV-8 present a similar morphology of the herpesviridae capsid, but their surface proteins differ, resulting in diverse mechanisms of cell infection. EBV infects B-lymphocytes through interaction of viral glycoprotein gp350/220 with a component of the complement receptor CD21. Infection of epithelial cells involves the receptor of immunoglobulin IgA $[11,16]$. Penetration of HHV-8 in host cells involves an interaction between a viral envelope glycoprotein gpK8.1 with a host membrane receptor, integrin $\alpha 3 \beta 1[1,16]$. This interaction promotes polymerization of microfilaments of the cytoskeleton, which leads to endocytosis of the virus particles in epithelial cells, Blymphocytes, macrophages and endothelial cells $[3,17]$. These differences may explain the different distribution of these viruses in the Waldeyer's ring, each organ presenting diverse adhesion molecules and chemokines, as demonstrated elsewhere $[2,14]$.

Latent infection of EBV and HHV-8 is involved in the pathogenesis of lymphoid, epithelial and endothelial neoplasms, including tumors of the Waldeyer's ring, a fact that justifies the increasing number of studies about these agents $[8,12]$. In this respect, our previous findings confirmed that lymphoid and, more infrequently, epithelial cells of the Waldeyer's ring represent sites of protracted residence of both viruses, though presenting differences in the frequency of positive cells and in the preference for the tonsil or adenoid $[5,9,10]$.

Another evident difference is the geographic distribution of EBV and HHV-8 in humans. While $\mathrm{HHV}-8$ is very infrequently detected in industrialized countries and is more prevalent in poorer regions (central Africa, Mediterranean Europe and north of South America) $[6,8,15]$, EBV is ubiquitous, with an estimated prevalence of more than $90 \%$ of individuals worldwide [12]. The above-mentioned factors may be responsible for the lack of correlation between the detection of EBV and HHV-8 in the tonsils studied herein. In this respect, the co-infection by both, as occurred in 17 of the patients in the present study seems just a coincidental event, as already discussed elsewhere [4].

Transmission of both viruses presents more similarities that previously suspected. EBV, traditionally considered to be spread by saliva, may be transmitted also by genital contact, blood transfusion and transplantation [12]. On the other hand, HHV8 , first considered to be genitally transmitted, especially among homosexual males, is increasingly being regarded as transmissible by the saliva $[5-7,15]$.

In conclusion, although belonging to the same $\gamma$ herpesviridae subfamily, our findings evidence that EBV and HHV-8 present differences in the frequency of detection in the Waldeyer's ring and in the predilection for the tonsils or adenoids $[5,9,10]$. Furthermore, the lack of correlation between the positivity for both viruses in the lymphoid organs studied indicate that predisposing factors, either 
environmental or constitutional, are independent. It is probable that differences in the lymphoid tissues' and in the viral's protein structure play a role in the pathogenesis of these findings $[2,14]$.

\section{Acknowledgements}

The authors acknowledge Mrs. Sirlei Siani Morais for help with statistical analysis.

The present study was supported by Fundação de Amparo à Pesquisa do Estado de São Paulo (FAPESP), grant 03/02380-3.

J.V. and W.L.C.S. are researchers of the Conselho Nacional de Pesquisas Científicas (CNPq), Brazil.

\section{References}

[1] S.M. Akula, N.P. Pramod, F.Z. Wang, B. Chandran, Integrin alpha3beta1 (CD 49c/29) is a cellular receptor for Kaposi's sarcoma-associated herpesvirus (KSHV/HHV-8) entry into the target cells, Cell 108 (2002) 407-419.

[2] D. Bourges, C.H. Wang, C. Chevaleyre, H. Salmon, T and IgA B-lymphocytes of the pharyngeal and palatine tonsils: differential expression of adhesion molecules and chemokines, Scand. J. Immunol. 60 (2004) 338-350.

[3] P. Brousset, E. Cesarman, F. Meggetto, L. Lamant, G. Delsol, Colocalization of the viral interleukin- 6 with latent nuclear antigen- 1 of human herpesvirus- 8 in endothelial spindle cells of Kaposi's sarcoma and lymphoid cells of multicentric Castleman's disease, Hum. Pathol. 32 (2001) 95-100.

[4] E. Caussinus, F. Meggetto, G. Delsol, P. Brousset, Simultaneous occurrence of Epstein-Barr virus associated Hodgkin's disease and HHV-8 related multicentric Castleman's disease: a fortuitous event? J. Clin. Pathol. 54 (2001) 790-791.

[5] C.A. Chagas, L. H. Endo, E. Sakano, G.A. Pinto, P. Brousset, J. Vassallo, Detection of herpesvirus type 8 (HHV8) in chil- dren's tonsils and adenoids by immunohistochemistry and in situ hybridization, Int. J. Pediatr. Otorhinolaryngol. 70 (2006) 65-72.

[6] L. Corey, S. Brodie, M.L. Huang, D.M. Koelle, A. Wald, HHV-8 infection: a model for reactivation and transmission, Rev. Med. Virol. 12 (2002) 47-63.

[7] P. De Paoli, Human herpesvirus 8: an update, Microbes Infect. 6 (2004) 328-335.

[8] D.C. Edelman, Human herpesvirus 8: a novel human pathogen, Virol. J. 2 (2005) 78-111.

[9] L.H. Endo, D. Ferreira, M.C. Montenegro, G.A. Pinto, A. Altemani, A.E. Bortoleto, J. Vassallo, Detection of EpsteinBarr virus in tonsillar tissue of children and the relationship with recurrent tonsillitis, Int. J. Pediatr. Otorhinolaryngol. 58 (2001) 9-15.

[10] L.H. Endo, J. Vassallo, E. Sakano, P. Brousset, Detection of Epstein-Barr virus and lymphoid subsets in adenoids from children under the age of 2 years, Int. J. Pediatr. Otorhinolaryngol. 66 (2002) 223-226.

[11] R. Kobayashi, H. Takeuchi, S. Sasaki, M. Hasegawa, K. Hirai, Detection of Epstein-Barr virus infection in the epithelial cells and lymphocytes of non-neoplastic tonsils by in situ hybridization and in situ PCR, Arch. Virol. 143 (1998) 803-813.

[12] K.F. Macsween, D.H. Crawford, Epstein-Barr virus: recent advances, Lancet Infect. Dis. 3 (2003) 131-140.

[13] D.J. McGeoch, A. Davidson, The descent of herpesvirus 8 , Cancer Biol. 9 (1999) 201-209.

[14] J. Nicholas, Human gammaherpesvirus cytokines and chemokine receptors, J. Interferon Cytokine Res. 25 (2005) $373-383$.

[15] L. Sarmati, HHV8 infection in African children, Herpes 11 (2004) 50-53.

[16] P.G. Spear, R. Longnecker, Herpesvirus entry: an update, J. Virol. 77 (2003) 10179-10185.

[17] S. Valmary, P. Richard, P. Brousset, Frequent detection of Kaposi's sarcoma herpesvirus in germinal centre macrophages from AIDS-related multicentric Castleman's disease, AIDS 19 (2005) 1229-1231.

[18] J. Vassallo, L.Z. Camargo, C.A. Chagas, G.A. Pinto, L.H. Endo, Search for herpesvirus 1 and 2 by in situ hybridization in tonsils and adenoids, Int. J. Pediatr. Otorhinolaryngol. 69 (2005) 345-349.

Available online at www.sciencedirect.com 